\title{
Investigation of molecular mechanisms using integrated analysis of transcriptomes and cytokinome in dermatomyositis
}

Jingjing Bai

Peking Union Medical College Hospital https://orcid.org/0000-0002-7367-241X

Chanyuan Wu

Peking Union Medical College Hospital

Danli Zhong

Peking Union Medical College Hospital

Dong Xu

Peking Union Medical College Hospital

Qian Wang ( $\nabla$ wangqian_pumch@126.com )

https://orcid.org/0000-0002-4541-9898

\section{Xiaofeng Zeng}

Peking Union Medical College Hospital

\section{Research article}

Keywords: cytokines, dermatomyositis, differentially expressed genes, Interferon Type I,

Posted Date: June 22nd, 2020

DOI: https://doi.org/10.21203/rs.2.24841/v2

License: (9) (i) This work is licensed under a Creative Commons Attribution 4.0 International License.

Read Full License 
The authors have withdrawn this preprint from Research Square 